This item was submitted to Loughborough's Research Repository by the author.

Items in Figshare are protected by copyright, with all rights reserved, unless otherwise indicated.

\title{
Discursive deracialization in talk about asylum seeking
}

PLEASE CITE THE PUBLISHED VERSION

http://dx.doi.org/10.1002/casp.1065

\section{PUBLISHER}

(c) John Wiley \& Sons, Ltd.

\section{VERSION}

AM (Accepted Manuscript)

\section{PUBLISHER STATEMENT}

This work is made available according to the conditions of the Creative Commons Attribution-NonCommercialNoDerivatives 4.0 International (CC BY-NC-ND 4.0) licence. Full details of this licence are available at: https://creativecommons.org/licenses/by-nc-nd/4.0/

\section{LICENCE}

CC BY-NC-ND 4.0

\section{REPOSITORY RECORD}

Goodman, Simon, and Shani Burke. 2019. "Discursive Deracialization in Talk About Asylum Seeking". figshare. https://hdl.handle.net/2134/16520. 


\title{
Discursive Deracialisation in talk about Asylum Seeking
}

Short Title: Discursive Deracialisation in asylum talk

\author{
Simon Goodman and Shani Burke \\ both at Coventry University
}

$\begin{array}{ll}\text { Please address all correspondence to the first author at } \\ \text { Work E-mail: } & \text { S.Goodman@Coventry.ac.uk } \\ \text { Private E-mail: } & \text { Simon.Goodman@yahoo.com } \\ \text { Office phone: } & +44(0) 2476888209 \\ \text { Office fax: } & +44(0) 2476888300 \\ \text { Home phone: } & +44(0) 2476678967\end{array}$

Correspondence Address:

Dr Simon Goodman

Department of Psychology (JS264)

Faculty of Health \& Life Sciences

Coventry University

Priory Street

Coventry

CV1 5FB

UK

Word count: $\quad 7,846$ 


\title{
Discursive Deracialisation in talk about Asylum Seeking
}

\author{
Abstract \\ In this paper we explore the extent to which 'discursive deracialisation', the removal of 'race' \\ from potentially racially motivated arguments, is taking place in talk about asylum seeking. A \\ discourse analysis is conducted on the part of a corpus of data collected from focus groups with \\ undergraduate students talking about asylum seeking, in which they were asked if they \\ considered it to be racist to oppose asylum. We show that speakers use three arguments for \\ opposing asylum that are explicitly non-racist: opposition is based on (1) economic reasons (2) \\ religious grounds and the associated threat of terrorism and (3) the lack of asylum seekers' \\ ability to integrate into British society. These findings are discussed with regard to the \\ implications they have for our understanding of discursive deracialisation in which it is shown \\ that there is a common knowledge understanding, albeit one that needs qualifying, that \\ opposition to asylum is not racist.
}

Key words: Discursive Deracialisation, Asylum Seekers, Discursive Psychology, Prejudice, Racism

\section{Introduction}

Despite the continuing harsh treatment towards asylum seekers (e.g. Bloch \& Schuster, 2005; Every \& Augoustinos, 2007; Hynes \& Sales, 2009; Leudar et al, 2008; Randall, 2003) there is an ongoing debate about whether or not such opposition to asylum seekers is racist. While a number of commentators and politicians maintain that opposition is not racist (e.g. the UK's Conservative party) other commentators (e.g. Hubbard, 2005) including discursive psychologists (Every \& Augoustinos, 2007; Lynn \& Lea, 2005) have argued that this opposition is in the very least prejudicial. Of particular interest is the finding that supporters of asylum seeking may not freely make accusations of racism without bringing about a negative appraisal (Goodman, in press; van Dijk, 1992, 1993). This current discursive analysis contributes to this 
ongoing debate (Capdevila \& Callaghan, 2008; Figgou \& Condor, 2006) by addressing how undergraduate focus group participants respond to the question 'is it racist to oppose asylum seeking?' In particular we focus on cases where alternative explanations for racism are given for opposition to asylum seeking.

\section{Discursive psychology and prejudice:}

Throughout its history Discursive Psychology (henceforth DP) has been used to address prejudice and racism. Wetherell \& Potter (1992) showed that talk does not need to be obviously racist or prejudicial to bring about and justify the prejudicial and oppressive treatment of particular groups. This is what discursive psychologists mean when they refer to the 'action orientation' of talk (Edwards \& Potter, 1992) as it is what is achieved through talk, rather than what this talk tells us about people's attitudes that is of interest in DP. Another key tenet of DP of prejudice is the existence of the 'norm against prejudice' (Billig, 1988, p.95) in which speakers can be seen going to rhetorical lengths not to be labelled as racist as this is a damaging subject position with which to be associated. DP has been used to show that to avoid being seen as prejudiced, or racist, people use disclaimers (Hewitt \& Stokes, 1975, such as 'I'm not prejudiced, but...', Billig et al, 1988, p.112) to ensure that what they are saying is not taken as evidence of prejudice.

One way of broadly disclaiming prejudice is what Augoustinos and Every describe as 'Discursive Deracialisation' (2007, p.133). This is where speakers try to ensure that their opposition to outgroups is attributed to reasons other than race. This finding is supported by many analyses (e.g. Capdevila \& Callaghan, 2008; Lynn \& Lea, 2003). Augoustinos \& Every (2007) suggest that this explains the increase in talk about 'nationality' (rather than race) in anti-immigration and asylum arguments. Coinciding with this 'discursive deracialisation' is the suggestion that in addition to the well established 'norm against prejudice' (Billig, 1988, p.95) that there is an increasing norm against making accusations of racism. van Dijk (1992) has shown how this 
taboo against prejudice can be utilised by speakers to claim that majority groups are being discriminated against because they are not allowed to speak their mind. Goodman (in press) has shown how opponents of asylum (and immigration) take this a step further so as to present the norm against prejudice as an assault on free speech to the extent that making accusations of racism has become problematic for supporters of asylum.

Another feature of discursive deracialisation is that instead of presenting opposition to outgroups as in any way prejudicial, speakers present alternative explanations that draw upon reasonableness to explain their opposition. This is to be expected considering Edward's claim that 'any kind of prejudice is tantamount to irrationality' (2003, p.40, emphasis in original) and that people will not want to appear irrational. Capdevila \& Callaghan (2008) have shown this to be a key feature of the UK's Conservative party's anti asylum and immigration campaign in which they explicitly claimed that their opposition to asylum was not racist, but was common sense. They also show how the party's leader Michael Howard constructed himself as a reasonable (and therefore not racist) man. Another example of building such cases as reasonable, and so not racist, was identified by Augoustinos et al (1999) in which opposition to Aborigines in Australia was presented as due to (reasonable) opposition to the government favouring Aborigines over white Australians.

This current analysis draws together a number of these themes by looking at the way in which student participants construct alternative, non-racist (discursively deracialised) and reasonable explanations for opposing asylum seekers when asked if it is racist to oppose asylum seeking.

\section{Procedure}

The data in this analysis is part of a corpus generated for an ongoing research project about how students talk about asylum. This project is distinct in that the data has been collected using focus groups with undergraduate students rather than from media or parliamentary data (e.g. Every \& Augoustinos, 2007). Five focus groups were conducted with sixteen psychology 
undergraduate students (fifteen female with a range of ethnic backgrounds, reflecting the makeup of the course) at a UK University between October 2008 and April 2009. The voluntary nature of participation, coupled with the distinct demographic of undergraduates does mean that this corpus may not be representative of the entire population, although a range of views and repertoires were displayed. The focus groups were led by the first author and covered a range of issues relating to asylum seeking, however this analysis was conducted on only the responses to the interviewer's question: 'is it racist to oppose asylum seeking?' This is because of an interest in what constitutes racism both generally (e.g. Figgou \& Condor, 2006) and within the asylum debate (e.g. Every \& Augoustinos, 2007).

Focus group research has been shown to be ideal for generating interaction between participants (e.g. Puchta \& Potter, 2004) which has been the case in this data corpus. Those who argue against 'contrived' data as a source of discursive analysis (e.g. Potter, 1997) claim that participants will be attending to the 'performance' of being in a focus group which may affect the data. However, as Speer (2002) has argued, a 'natural' and 'contrived' distinction may not exist because participants are always producing their own ('natural') accounts while attending to whatever ('contrived') social situation they are in, which in this case is a focus group.

This research is part of the increasing body of (broadly critical) discursive psychological (e.g. Wetherell \& Edley, 1999) analyses that have looked at talk (and texts) about asylum seekers, and in particular how their harsh treatment is justified (Every \& Augoustinos, 2007, Goodman 2007, 2008, in press, Goodman \& Speer, 2007; Goodman \& Burke, in press; Leudar et al., 2008; Lynn \& Lea, 2003; Verkuyten, 2005). Such research focuses on the action orientation of talk (Edwards \& Potter, 1992) which means that our interest lies in what is accomplished in the interaction, rather than what talk may tell us about speakers' internal cognitions. 
To conduct the analysis the data were transcribed according to Jeffersonian conventions (Atkinson and Heritage, 1984 pix-xvi). In this analysis the authors focused on cases in the data where participants offered alternatives to racism as an explanation of opposition to asylum seeking. The extracts featured were chosen as exemplars of the strategies indentified in the analysis.

\section{Analysis}

We have identified three strategies that were used in the focus groups to represent non-racist explanations for opposing asylum. The most prevalent was that opposition to asylum is due to economic reasons, however opposition was also attributed to religion and (a lack of) integration. Each of these will be addressed in turn.

\section{It's not racist; it's about the economy}

In the following extracts we see examples of speakers arguing that economic reasons better explain opposition to asylum than racism does. Such arguments are usually made in a delicate way which suggests that participants orient to it as a matter that requires care. In this first extract, from FG3, we see P2 managing the dilemma caused by posing the question 'is it racist to oppose asylum seeking?' by first suggesting how it can be racist before settling on non-racist economic reasons.

Extract 1: FG3 Financial bit, living off us

1. P2: [sorry erm] >I was j-gonna say<'cause you are oppo:sing

2. foreigners

3. SG: yeah

4. P2: and if you sort of hate em $>$ due to the fact that $-<$ of their nationality: (.)

5. ra:ce (.) skin colour >all the rest of $<i:: t(0.3)$ then that is being raci::st 
6. SG: okay

7. P2: if you just $h-(0.4)$ oppose the who:l:e (0.6) asylum seeking system $>s$ - in

8. the (sense) that< (0.5) oh:: (.) they're living off us

9. SG: hmm:

10. P2: >in the sense that< it's all basic- (.) on (0.4) based around (0.8) the whole

11. financial bit of it

12. SG: yeah?

13. P2: =then $\uparrow$ I suppose that's not really being raci:st [you]'re just saying

14. SG:

[okay:]

15. P2: $\quad y^{\prime}$ know (.) they're living off us

In the first half of this extract P2 puts forward a definition of what does count as racist. This is brought about through the listing of characteristics on which racism is based (1:5). This lay representation of racism is explicitly attributed to hating people from different (ethnic) backgrounds (see Figgou \& Condor, 2006). This construction of opposition to asylum as racist is then contrasted (Atkinson, 1984) with a non racist explanation, directly following the interviewer's continuer (1:6). Here, rather than opposing individual asylum seekers the opposition is now constructed as being directed at the system (1:7). Notice the use of 'just' (1:7) which has been shown to downgrade and criticise what is being said (Goodman \& Burke, in press). This position, which is based on an economic argument that asylum seekers do not pay their way (e.g. Goodman \& Speer, 2007; Lynn \& Lea, 2003, which is associated with the idea of the 'economic migrant', see Laytonn-Henry, 1992; Steiner, 2000) is placed as outside of the speaker. This can be seen through the use of 'oh' which has been shown to highlight 
reported speech (Myers, 1999). By showing that this idea is not her own, P2 is able to dissociate herself from this position which suggests that $\mathrm{P} 2$ is orienting to this position as being a potentially damaging one. This shows the dilemmatic nature (e.g. Billig et al, 1988) of the issue with $\mathrm{P} 2$ hedging so as not to align with either the position that it is, or is not, racist to oppose asylum, while pointing out the flaws of both positions.

The use of 'I suppose' (1:13) does suggest that on the basis of the two sides of the argument P2 has reasonably concluded, albeit rather tentatively, that it is not racist to oppose asylum seeking given the economic burden ('living off us' (1:15)) that they cause British people to endure. The use of ' $y$ 'know' (1:15) is an appeal to common knowledge (Edwards \& Potter, 1992). Nevertheless, this non-racist reason for opposing asylum seeking is still not taken up as the speaker's own view as P2 is speaking on behalf of others (you're just saying $1: 13$ ) rather than herself. This is of interest because even though P2 is not claiming this position as her own, she is still going to some rhetorical length to disclaim racism on behalf of others (Condor et al, 2006).

In the following extract we see a similar structure used. It begins with an acknowledgment of how opposition to asylum may be racist and ends with the speaker suggesting that this opposition is most likely due to non racist - economic - reasons.

Extract 2: FG4 Lack of jobs, slums and all that

1. P1: [ye:s] (.) yeah ye:s because: (0.6) the people: (.) that are getting

2. deni:ed or .hh >the people that you're opposing < are different race to you

3. .h so you can put in the context of o:h you don't wa:nt that certain race

4. (.) .hh here for whatever reason .hh but then no: because: (1.0) the

5. $\quad$ reasons why: (0.8) th- $\mathrm{m}$ - like people oppose asylum .hh is not 
6. necessarily down to (.) the colour $r$ - they are it's the (.) .hh the

7. consequences of them coming over sort of like .hh l:ack of jo::bs: an::

8. you know slum:s being: develo 1 ped and all that .hh s:o (1.0) I think it's (.)

9. I think it's a mixture of both really I $f->\mid$ don't think you can< put it o::n

10. (0.5) and say yeah it's a racist thing (0.6) unle- unti:l: sort of prejudice

11. statements start being ma:de and (.) then it becomes about race .hh

12. but $(0.6)>I$ don't know< I think it's $\uparrow I$ think it's a bit of bo:th to be honest

13. SG: $\quad$ right (.) okay

14. P1: =definite

15. ?: $\quad \mathrm{hmm}$

16. (2.0)

17. P2: $\quad$.h yea:h I pretty much agree: (.) I think it (.) y-yeah (1.3) depends w:hat

18. they (.) what they (.) what the context is kind of

19. P1: $\quad$ yeah

P1 begins this account by suggesting the ways in which opposing asylum seeking can be racist. This begins with a repeatedly emphasised 'yes, yeah, yes' (2:1) and a suggestion that opposing asylum seekers is a manifestation of opposing people from a different race, as in extract one. Again we see the use of 'oh' (1:3) to signal reported speech which distances the speaker from the views expressed. The contrast comes at line four ('but then no') when P1 switches to arguing the case that it is not racist to oppose asylum. The 'no' (1:4) is emphasised just as the earlier agreement was. Again the speaker dissociates her comments from those being 
described ('people oppose asylum' 1:5) and so avoids aligning with either the position that it is - or is not - racist to oppose asylum seeking.

The non-racist reasons for opposing asylum are constructed as the financial 'consequences' (2:7) of asylum. These are presented in a three-part list (Jefferson, 1990) including (1) 'lack of jobs' (2:7) and (2) 'slums being developed (2:8) and is concluded with a general 'and all that' (2:8). While the economic arguments are often cited in debates about asylum (Capdevila \& Callaghan, 2008; Goodman \& Speer, 2007; Lynn \& Lea, 2003) one of the specific reasons offered here 'the development of slums' is more unusual. It is unclear exactly what is meant by this or where such an argument may have come from and suggests a lack of a sophisticated understanding of the asylum issue.

P1 then struggles to align with either of the alternatives that have been offered, which can be seen through the pauses, elongation and repetition of words which suggest that this is a dispreferred response (Pomerantz, 1984). It is interesting that P1 says that for the opposing of asylum seekers to be considered racist there must be accompanying 'prejudice statements' (2:10/11) which suggests that opposition to asylum alone is not considered to be prejudicial (despite the arguments that the mistreatment of this group may well be prejudicial e.g. Hubbard, 2005). P1 then completes this hedging turn by claiming ignorance ('I don't know' 2:12) which again allows the speaker to avoid making a definite decision, and allows for the question to not be properly answered ('it's a bit of both' $12: 12)$. The use of 'to be honest' (2:12) highlights the contentious and dilemmatic nature of the question, as claims of honesty have been shown to be a feature of talk about contentious issues (Edwards \& Fasulo, 2006).

Next, P2 supports P1's earlier comments. Again, however, the alignment with this position, which is itself a tentative one, is managed with delicacy that allows the speaker room to move from this position: this can be seen in the term 'I pretty much agree' (2:17) and the long pauses 
throughout this brief statement. P1 then follows this with another token of agreement which shows that $\mathrm{P} 1$ and $\mathrm{P} 2$ are building this account together.

In this final extract in the section we can see an extra element added to the discussion about economic reasons for opposing asylum. Here there is debate about the motivations of opponents of asylum based on their own ethnic status: suggesting that it is easier for people from ethnic minorities to oppose asylum seekers without being seen as racist.

\section{Extract 3: FG4 Economic reasons}

1. P2: wher::eas: (2.0) if (.) 个you know you are part of av- (.) a minority then

2. (.) .hh (1.5) 个the:n I think yeah people ar:: (.) are more (.) you can-

3. you can say it I think .hh

4. SG: $\quad{ }^{\circ} \mathrm{okay}^{\circ}$

5. P2: but at the same time I think that (1.3) 个I don't know I think that if::

6. $\quad$ if a person< (.) from minority groups: does: (1.3) say e::: (1.3)

7. I don't know (.) if they oppose kind of asylum seeking .hh 个you think (0.2)

8. $\quad>$ I don't know< it's re:- it's confusing 'cause (2.3) y-it has to be (.) er I

9. think it's taken more as in (0.2) okay (.) i:t's like (.) econom- it must be

10. econ $\uparrow$ omic reas $\downarrow$ ons rather than

11. SG: right

12. P2: like (0.2) anything other -like any ra:cial issues 
In many ways this extract follows a similar structure to those above. There is an explicit acknowledgment that this is a contentious and problematic question to answer directly (e.g. 'it's confusing' 3:8). The speaker then draws on the now commonly recognised repertoire of opposing asylum on economic grounds (as in extracts one and two). Where this extract is different is the suggestion of another variable that influences whether or not opposition to asylum can be seen as either based on racism or economic reasons and this factor is the race of the opponent of asylum. It is suggested that people from minorities are more likely to be seen as opposing asylum for economic reasons whereas white people are more likely to be seen as opposing asylum for racial reasons. In this particular case it is implied that it is particularly difficult to oppose asylum without being seen as racist and that it is only members of ethnic minorities who are unlikely to be seen in this way. This argument is therefore implicitly critical of the 'taboo against racism' (Billig, 1988) which is presented as an assault of free speech (Goodman, in press). This can be seen in the emphasised comment that minorities 'can' (3:3) oppose racism without being seen as racist, which suggests that there is a lack of freedom for majority groups to be able to say what they want.

As with the previous extracts a noticeable feature of this talk is the large amount of hedging and delicacy displayed. On lines one to three we can see a number of pauses (including two over a second long) and a cut off word ('av' 3:1). More evidence of the hedging going on here is in the repeated use of 'I think' $(3: 2,3,4,4)$ which allows some space for the speaker to take back what is said. This suggests that the answer is a dispreferred response (Pomerantz, 1984) in that the presentation of the argument highlights the contentious nature of what is being said and the potentially negative appraisal that this can bring the speaker. Further evidence of the dilemmatic nature of this talk is the explicit claim that the issue is 'confusing' (3:8). While claiming to be confused could be seen as a negative self assessment to be made by a speaker, such a claim helps the speaker to maintain some distance from the (tentative) comments that are being made which means that in the event of being criticised for the comments they can 
relatively easily be removed without the accountability (Edwards \& Potter, 1992) of the speaker being seriously damaged.

In this extract P2 avoids giving a personal opinion about the reasons that people oppose asylum seeking. The point is made that it is difficult for white people to make anti asylum arguments without being seen as racist, which implies that there are non-racist reasons for opposition. Economic reasons are posited as a likely explanation for minority groups' opposition; however P2 offers no suggestion as to why people would use either argument, or the value of any such argument. This is different to the first two extracts in which the speaker aligns (to some extent) with both arguments as possible reasons for the opposition.

These extracts have shown that while participants acknowledge that opposition to asylum may be racist, an alternative argument - that this opposition is down to economic reasons - is also offered and to some extent favoured over the racist explanation. This favouring can be seen by the structure of the contrast, in which the first part (that opposition is racist) is placed before the favoured argument (that opposition is due to economic reasons) to give the second part of the contrast pair more weight (Atkinson, 1984).

In the following section we show how as well as the economic argument for opposing asylum a common theme in one of the focus groups (FG5) was that asylum may be opposed on religious grounds. In particular, this different religion is associated with a threat of terrorism. In this next extract we see a participant suggesting that people may be opposing asylum due to the religion of asylum seekers.

\section{It's not racism; it's about religion and terrorism}

Extract 4a: FG5 Religion, terrorism

1. P1: i think it is: because of (1.0) their religion where they're from 
2. SG: $\quad \operatorname{rig}[\mathrm{ht}]$

3. P1: $\quad[i$ d $]$ o: think it counts

4. SG: okay

5. P1: not $m E$ I DOn't think like that but I know pe- a lot of people think like that

6. SG: so religio:n more than race maybe:?

7. P1: yeah

8. P2: I think at the

9. moment wi[th all the te]rrorist issues it's reli:gion more [than race]

As with previous extracts there is some hedging and a long pause before the main point is made and as in extract three 'I think' (4:1) allows for some potential distancing from the point being made. It is noteworthy that after mentioning religion as a possible cause of opposition to asylum that another reason 'where they're from' (4:1) is suggested. The country of origin of asylum seekers is rarely given as a reason to oppose asylum (no other cases of this occur in this data corpus) and here seems to be closely associated with religion. Country of origin is given as an alternative reason to racism, despite the possible counter-argument that could be made that opposition of this kind may be deemed racist. The linking of religion and country of origin does suggest that a particular stereotype of asylum seekers (that of Muslims from the MiddleEast) is being used here (despite the evidence suggesting that many asylum seekers are from other countries and are not Muslim, see Home Office, 2008). Nevertheless, this route of argument is not pursued and P1 next refers to religion (4:6) only, five lines later.

However following the interviewer's continuer (4:4) P1 appears to backtrack somewhat and positions herself as someone commenting on the suggestion that opposition is based on religion and country of origin rather than holding the view personally. This can be seen through 
the loud talk accompanying this denial (4:5) that suggests urgency on the part of the speaker to ensure that this position is not attributed personally to her. By saying that 'a lot of people think that' (4:5) P1 positions herself as a commentator rather than a participant in the debate and so both adds credibility to her claim and rhetorically dissociates herself from this view. The interviewer's reformulation of this claim (4:6) is met with a confirmation from P1 (4:7) which suggests that this reformulation is accepted as fair. At this point $\mathrm{P} 2$ enters the discussion and as well as backing up P1's position goes on to make an explicit link between religion and terrorism. Unlike P1 who dissociated herself from the position, P2 claims ownership of this point by saying 'I think' (4:8). The use of 'at the moment' (4:9) serves to place this situation in a particular timeframe which means that P2 can easily respond to any challenges that this has not always been the case and may not be the case again. 'All the terrorist issues' (4:9) is something of a gloss over a very dominant repertoire of the threat of terrorism and the war on terror (see Leudar et al., 2004). To be able to gloss such a significant repertoire shows that not only is this an appeal to common knowledge, but also that P2 orients to this knowledge as self evident, so that no attempt to qualify this point is needed.

It is the 'terrorist issue' (4:9) that is used to account for how the religion of asylum seekers may currently be enough grounds to oppose asylum seeking to the UK. What is unsaid here is that the linking of religion to terrorism implicates only one religion: Islam. This therefore suggests that as well as expecting a common knowledge, cultural understanding of the 'problem' of terrorism, $\mathrm{P} 2$ also orients to the expectation that asylum seekers are seen as being Muslim, and most likely from the part of the world ('where they're from' 4:1) associated with 'the war on terror' and terrorism; the Middle-East. While the literature shows that there are indeed many asylum seekers (and recognised refugees) from the Middle-East, it also shows that many asylum seekers are not from this region (e.g. Home Office, 2008), nor have any terrorist attacks been perpetrated by asylum seekers in the UK. Nevertheless, this point is not mentioned 
throughout the focus group, which leaves the assumption that most asylum seekers are Muslim (and possible terrorist) unchallenged.

Following on from this extract the focus group topic is diverted briefly before P2 continues this argument 15 lines later. This time P4 enters the conversation and builds the account of opposition to asylum being based on the threat of terrorism collaboratively with P2.

Extract 4b: FG5 Religion, terrorism

10. P2: I think religion is probably a bit of a (.) issue at the minute $>$ but that's $<$

11. more be[cause] of the terrorists [attacks] th[at ha]ve been going

12. P4: [yeah ] [mm:: ]

13. SG: [right]

14. P2: on [like ] you know (0.8) sh- [(.) some (stewdies)] would be saying

15. P4: [yeah] [I think the (meed) ]

16. P2: muslim and the: li:ke (0.8) .hh ${ }^{\circ}$ I don’t want

17. them $^{\circ}[>\text { they're gonna] be bombers }<]^{\prime}$

18. ?: $\quad[(($ laughs $)) \quad]$

19. P4: [they're doing (.) ] the media's portrayed like every

20. muslim to be an extreme:ist

21. SG: right

22. P4: =and every like (.) sort of (.) that sort of religion to b:e: an an extreme:ist

23. SG: ri:ght ${ }^{\circ} \mathrm{okay}^{\circ}$ 
24. P4: =and (.) that's what people think when they hear (0.4) muslim and t-

25. um (0.4) like religions like that (0.3) they just think (.) extremist (.)

26. um (1.8) terrori:st

At the start of this part of the extract P2 repeats her comment about religion based opposition to asylum being due on the threat of terrorism. This repeat uses a very similar structure to the earlier comment. Again 'I think' (4:10) is used and 'at the minute' (4:10) does the same work as 'at the moment' (4:8/9) to suggest that this is a contemporary issue that has not, and may not, always be the case. Again this opposition is attributed to the threat of terrorism. While this statement does emphasise the 'problematic' status of Islam in contemporary Britain, it does have the effect of disclaiming that British people are opposed to foreigners or different religions without reason. Instead this statement suggests that they are only opposed to potential terrorists and that this opposition will only last as long as the terrorist threat does. This means that any hostility is not due to British opponents of asylum, but to terrorists. Such a strategy can work in a similar way to 'differentiating the other' (Lynn \& Lea, 2003) in which potential ('bogus') asylum cheats are used to justify the opposition to all asylum seekers.

P4 signals agreement with P2 (4:12) in overlap. P2 and P4 then speak together and build an account of what other people say (as with P1 above they are positioning themselves as commentators rather than participants in the debate). On line 16 the religion in question that is being opposed is explicitly named for the first time ('Muslim', 4:16). After the religion is named P2 offers her account with much delicacy. This can be seen by the long pause (4:16) and the quietly and quickly delivered words (4:16/17). While P2 displays delicacy, her comments are met with laughter. This laughter could suggest that this point is considered to be amusing, or perhaps shows that it is a delicate and contentious matter. Nevertheless, after this comment and the associated laughter P4 explains why people may be opposed to asylum seekers and 
lays the blame directly with the 'media' (4:19) for linking Muslims with terrorism. P4 uses an extreme case formulation (4:19; Pomerantz, 1986) to criticise the media for exaggerating. This helps to construct the media as accountable for any hostility to asylum seekers by rendering people unable to dissociate Muslims from the notion of terrorism (4:24-26).

After P4's turn there is another 15 lines of talk in which P1 gives an account of an unspecified Muslim who allegedly had called for a mass immigration of 'Asians' into Britain so as to replace the culture of the country with an Asian one. After this, P2 completes her account by contrasting opposition to race with opposition to religion to show that opposition to asylum is not racist, but is based on the problems of religion and terrorism.

\section{Extract 4c: FG5 Religion}

27. P2: I don't know it's- (1.0) $\uparrow$ do you call people $\downarrow$ if you're against >somebody's

28. religion< is that being racialist? (0.2) that's not being racist is it 'cause

29. that's not

30. P3: $\quad{ }^{\circ}$ prejudice I suppose ${ }^{\circ}$

31. P1: myeah

32. P2: because he- (.) I think (.) at this moment in ti::me the ma- (.) like (.)

33. there'd be quite a fe: w people if you had (.) a black christian person (.) or

34. a white muslim pers:0:n (0.4) >they'd be a lot more prejudicst< against

35. (.) the white muslim per[son (.) becau]se of the (.) current (.) social (.)

36. SG:

[right okay ]

37. P2: standing like 
P2 seeks to give credibility to the idea that opposition to asylum is based on religion rather than race in two ways. First she seeks to give a formal name to this kind opposition. She suggests that it can be called racism, in the form of a rhetorical question (4:28), only to reject this term as inaccurate with the support of P3's correction 'prejudice' (4:30), and P1's agreement (4:31). Second, P2 builds a more detailed account where she contrasts religious opposition with racial opposition to highlight that any opposition to asylum is religiously motivated. Again, this is attributed to contemporary issues (4:32 and 35) which once more shows that this is a legitimate intolerance brought about by terrorists rather than any prejudice inherent in the British population.

In this final extract we can see both economic and religious reasons for opposing asylum brought together under the umbrella of integration where asylum seekers are presented as incompatible with British society.

\section{It's not racism; it's about integration.}

Extract 5: FG5 Integration, taking our jobs, taking our women

1. P3: I'd- (.) I think it's mainly to do with integra:tion which (.) does link with the

2. P4: =yeah

3. P3: =religion (0.4) [being int] egrated in society if it's (.) .hh separate

4. SG: [right ]

5. P3: everything's separate: an then it seems like you're just (.) coming in (.)

6. doing your own thing taking our jo:bs (.) taking (.) .hh like .hh el- even

7. (.) some: (.) might even think oh y'know taking our women kind of things:

8. some [men] might sa:y th[a::t you never know (.) um ] ((laughs)) (0.7) 
9. SG: [right]

10. ?:

[yeah yeah I can I can ( ) ]

11. P3: $\quad$ or whatever (0.7) so (0.8) I dunno th- they might come and $(0.7)$ think $>$ I

12. think it's that's< what it is integra:tio:n (.) mai:nly: [they're not integrate:d]

Ten lines after extract 4, P3 seeks to associate the issue of religion with integration. This can be seen with the emphasis on 'does' (5:1). P3 then supports this case for a lack of integration by way of a list which includes the asylum seekers doing their own thing, taking jobs and taking women. This account works to build the asylum seeking 'other' as particularly problematic. This listing of problems combined with the reference to 'you' (5:5) and 'our' (5:6) and 'doing your own thing' (5:6) shows that an 'us and them' distinction (or in this case separation 5:5), so common in talk about asylum seeking (Goodman, 2007; Lynn \& Lea, 2003; Mehan, 1997; Van der Valk, 2003; van Dijk, 1993, 1997; Verkuyten, 2001, 2005) is present here. The reference to jobs shows the speaker drawing on the 'economic reasons to oppose asylum' repertoire identified above, however the 'taking our' (5:6) part of this suggests that the asylum seekers are actively damaging the existing population rather than this being a consequence of them being here ${ }^{1}$.

P3 then takes this account even further by suggesting that it could be said that asylum seekers are even here to take the country's women. This is a peculiar remark as it is made by a female participant, however the comment is presented as reported speech (signalled by 'oh' 5:7) and so not considered to be the speaker's own words. P3 highlights that what she just said was quite extreme by shifting her footing (Goffman, 1981) to show that it is possible that men could say that. Her laughter after this further highlights the comical nature of such an extreme comment. After this laughter (which is not met with laughter or any comments from anyone

\footnotetext{
${ }^{1}$ Asylum seekers are legally banned from working in the U.K. (Sales, 2002)
} 
else in the group) there is a serious of long pauses and continuing terms ('whatever' and 'so' 5:11) before $\mathrm{P} 3$ shows signs of faltering in this argument ('dunno' 5:11) and returning to the point about integration. While the point about taking 'our' women didn't appear to support her argument about lack of integration this turn still functions to present asylum seekers as 'other' and as a threat to the British way of life. This seems to be consistent with other anti-asylum arguments that suggest that asylum can be damaging to British culture (Goodman, in press). This post functions to bring about a construction of asylum seekers as both an economic problem and as a threat to the country's culture while denying that such opposition is racist.

\section{Conclusions}

This analysis has addressed explanations for opposing asylum seeking that are favoured over representing this opposition as racist. Three major arguments were identified as alternatives to racism: (1) that asylum is opposed for economic reasons (2) that asylum is opposed because asylum seekers are of a different religion and therefore may be terrorists and (3) that asylum seekers may not integrate into existing society.

That opposition to asylum is constructed as due to economic reasons by participants has been identified in discursive analyses as being used in the media and by politicians (see Capdevila \& Callaghan, 2008; Goodman \& Speer, 2007; Lynn \& Lea, 2003). What is of particular interest is that the economic argument is used here by students and is explicitly favoured at precisely the point at which it is suggested (by the interviewer's question) that opposition to asylum may be racist. This suggests that a repertoire of 'economic opposition to asylum' is utilised to produce 'discursive deracialisation' (Augoustinos \& Every, 2007, p.133) within the interaction. We have therefore shown that discursive deracialisation can be seen as a participant's strategy in interaction in talk about asylum. Nevertheless, a great deal of delicacy is displayed when participants use this argument which suggests that they are orienting to the controversial nature of the claim. While this appears to be a commonly used argument it is therefore by no 
means taken for granted as common knowledge (Edwards \& Potter, 1992). Speakers tended to present this position as part of a contrast structure in which the non-racist (favoured) argument was placed in the second part of the contrast to give it more rhetorical strength.

Another notable strategy aimed at producing discursive deracialisation was the strategy of attributing opposition to asylum on religious grounds. In many ways this strategy is typical of discursive deracialisation. As Every and Augoustinos show

exclusionary views and practices can be legitimated and warranted through the use of culture, rather than race, as a marker of difference. ... In this culture-as-natural difference discourse, the Other is constituted as inferior in their cultural practices, attitudes and values, and as a threat to the dominant culture (2007, p.413)

The linking of asylum seekers with terrorism has been shown to be made in the media (e.g. Leudar et al., 2008; Randal, 2003) and this analysis has shown that it is also used by undergraduate participants as an alternative - reasonable - explanation for opposing asylum. This claim is presented as belonging to other people rather than the speakers themselves which suggests some attempt by speakers to dissociate themselves personally with this view. The use of this strategy shows that the threat of terrorism is an important repertoire in contemporary society and that this threat is used to oppose contact with out-groups, even when these groups may not be directly involved in terrorism (as is the case with asylum seekers). This strategy also positions asylum seekers as particularly distinct from the British 'us' both religiously and culturally (which also shows that the issues of religion and culture are distinguished from race). This represents an extreme version of the 'us and them' dichotomy that has been shown to be common in asylum talk (Goodman, 2007; Lynn \& Lea, 2003; Mehan, 1997; Van der Valk, 2003; van Dijk, 1993, 1997; Verkuyten, 2001, 2005): here asylum seekers are potential terrorists who represent a threat to our safety. This is a strong rhetorical device 
based upon the myth of the threat of terrorism posed by asylum seeking which justifies a failure to help, and the harsh treatment of, asylum seekers.

The final argument used as an alternative to racism in explaining opposition to asylum was that asylum seekers are unable to integrate into British society. This argument was closely linked with those based on the different religion of asylum seekers and the threat of terrorism they may bring. This again shows an orientation to what Every and Augoustinos called the 'cultureas-natural discourse' (2007, p.413) and uses the 'us and them' dichotomy to represent asylum seekers as incompatible with 'us'.

Another interesting finding of this analysis is that once again it is argued that it is easier for minorities than whites to make anti-asylum arguments. This shows an orientation to the criticisms of the 'norm against prejudice' (Billig, 1988, p.95) in which this norm is presented as unfair towards majority groups (Goodman, in press; van Dijk, 1992) which means that only minority groups can be seen to oppose asylum without the threat of being accused of racism (Goodman \& Burke, in press).

This analysis has shown that there appears to be a move towards a common knowledge (Edwards \& Potter, 1992) understanding that opposition to asylum is not based on racism, but on other - more reasonable - grounds, and in particular because of economic practicalities. We have shown, however, that discursive work is nevertheless required to bring about such a construction which suggests that there is still room for debate about this point. It does seem, however, that opposition to asylum in the main is oriented to as a reasonable (non-racist) outcome of economic scarcity; much to the detriment of people fleeing persecution.

\section{References}


Atkinson, J. (1984). Public Speaking and Audience Responses: Some Techniques for Inviting Applause. In J. Atkinson and J. Heritage Structures of Social Action: Studies in Conversation Analysis. (pp.370-409) Cambridge, Cambridge University Press.

Atkinson, J. \& Heritage, J. (1984). Structures of Social Action: Studies in Conversation Analysis. Cambridge, Cambridge University Press.

Augoustinos, M \& Every, D (2007) 'The Language of "Race" and Prejudice: A Discourse of Denial, Reason, and Liberal-Practical Politics', Journal of Language and Social Psychology 26(2), 123-141

Augoustinos, M., Tuffin, K., \& Rapley, M. (1999). 'Genocide or a failure to gel? Racism, history and nationalism in Australian talk', Discourse and Society, 10, 351-378.

Billig, M. (1988). 'The Notion of 'Prejudice': Some Rhetorical and Ideological Aspects', Text 8(12), 91-110.

Billig, M., Condor, S., Edwards, D., Gane, M., Middleton, D., and Radley, A. (1988). Ideological Dilemmas. A Social Psychology of Everyday Thinking. London, Sage.

Bloch, A., \& Schuster, L. (2005). Asylum policy under New Labour, Benefits, 13, 115-118.

Capdevila, R \& Callaghan, J. (2008) 'It's not Racist. It's Common Sense'. A Critical Analysis of Political Discourse Around Asylum and Immigration in the UK, Journal of Community \& Applied Social Psychology, 18, 1-16

Condor, S., Figgou, L., Abell, J., Gibson, S., \& Stevenson, C. (2006). "They're not racist": Prejudice mitigation and suppression in dialogue, British Journal of Social Psychology, 45, 441-462.

Edwards, D. (2003). Analyzing Racial Discourse: The Discursive Psychology of Mind-World Relationships. In H. Van den Berg, Wetherell, M., and Houtkoop-Steenstra, H. Analyzing 
Race Talk: Multidisciplinary Approaches to the Interview (pp.31-48). Cambridge, Cambridge University Press.

Edwards, D \& Fasulo, A. (2006) "To Be Honest": Sequential Uses of Honesty Phrases in Talk-inInteraction. Research on Language and Social Interaction, 39(4), 343-376

Edwards, D. \& J. Potter (1992). Discursive Psychology. London, Sage.

Every, D \& Augoustinos, M (2007). Constructions of racism in the Australian parliamentary debates on Asylum Seekers, Discourse and Society, 18(4), 411-436

Figgou, L \& Condor, S (2006). Irrational Categorization, Natural Intolerance and Reasonable Discrimination: Lay Representations of Prejudice and Racism, British Journal of Social Psychology, 45, 219-243.

Goffman, E. (1981). Forms of Talk. Oxford, Blackwell.

Goodman, S (2007) Constructing Asylum Seeking Families. Critical Approaches to Discourse Analysis across Disciplines, 1(1), 35-49

Goodman, S (2008) Justifying the Harsh Treatment of Asylum Seekers on the Grounds of Social Cohesion, Annual Review of Critical Psychology, 6, 110-124

Goodman, S (in press). "It's not Racist to Impose Limits on Immigration": Constructing the Boundaries of Racism in the Asylum and Immigration debate, Critical Approaches to Discourse Analysis across Disciplines.

Goodman, S and Speer, S (2007) Category Use in the Construction of Asylum Seekers, Critical Discourse Studies, 4(2), 165-186 
Goodman, S \& Burke, S (in press) "Oh you don't want asylum seekers, oh you're just racist": A discursive analysis of discussions about whether it's racist to oppose asylum seeking, Discourse and Society.

Hewitt, J. P. \& Stokes, R. (1975). Disclaimers. American Sociological Review, 40, 1-11.

Home Office (2008) Asylum Statistics United Kingdom 2007. Home office statistical bulletin http://www.homeoffice.gov.uk/rds/pdfs08/hosb1108.pdf

Hubbard, P. (2005). Accommodating Otherness: Anti-Asylum Centre Protest and the Maintenance of White Privilege, Transactions of the Institute of British Geographers, $30(1), 52-65$.

Hynes, T. \& Sales, R. (2009) New Communities: Asylum Seekers and Dispersal In A. Bloch and J. Solomos (eds.) Race and Ethnicity in the 21st Century, Aldershot: Palgrave Macmillan

Jefferson, G. (1990). List Construction as a Task and Resource. In G. Psathas. Interaction Competence. (pp.63-92) Lanham, MD, University Press of America.

Laytonn-Henry, Z. (1992). The Politics of Immigration. Oxford, Blackwell.

Leudar, I., Marsland, V. and Nekvapil, J. (2004). On Membership Categorisation: 'Us', 'Them' and 'Doing Violence' in Political Discourse, Discourse \& Society, 15(2-3), 243-266.

Leudar, L., Hayes, J., Nekvapil, J., and Baker, J T. (2008) Hostility themes in media, community and refugee narratives, Discourse \& Society, 19(2), 187-221

Lynn, N. \& Lea, S (2003). 'A Phantom Menace and the New Apartheid': The Social Construction of Asylum-Seekers in the United Kingdom, Discourse and Society, 14(4), 425-452.

Lynn, N. \& Lea, S (2005). Graffiti and the Asylum Seeker: Text, Context and Social Comment, Visual Communication, 4, 39-63. 
Mehan, H. (1997). The Discourse of the Illegal Immigration Debate: A Case Study in the Politics of Representation, Discourse \& Society, 8(2), 249-270.

Myers, G. (1999). Functions of reported speech in group discussions, Applied Linguistics, 20(3), 376-401

Pomerantz, A. (1984). Agreeing and Disagreeing with Assessments: Some Features of Preferred/Dispreferred Turn Shapes. In J. Atkinson and J. Heritage Structures of Social Action: Studies in Conversation Analysis (pp79-112) Cambridge University Press.

Pomerantz, A. M. (1986) Extreme Case Formulations: A Way of Legitimizing Claims, Human Studies, 9, 219-30.

Potter, J. (1997) Discourse Analysis as a Way of Analysing Naturally Occurring Talk, in D. Silverman (ed.) Qualitative Research: Theory, Method and Practice, 144-60. London: Sage.

Puchta, C. \& Potter, J. (2004). Focus Group Practice. London: Sage

Randall, M. (2003). Guest Media Alert: Asylum and Immigration Comparing the Daily Telegraph, The Guardian and The Independent. Medialens, $8^{\text {th }}$ December. http://www.MediaLens.org/alerts/index.html

Sales, R. (2002). The Deserving and the Undeserving, Critical Social Policy, 22(3), 456-478.

Speer, S. (2002) 'Natural' and 'contrived' data: a sustainable distinction?, Discourse Studies, 4, $511-525$

Steiner, N. (2000). Arguing about Asylum. New York, St. Martins Press.

Van der Valk, I. (2003). Right-Wing Parliamentary Discourse on Immigration in France, Discourse \& Society, 14(3), 309-348. 
van Dijk, T. A. (1992). Discourse and the denial of racism, Discourse \& Society, 3, 87-118.

van Dijk, T A (1993) Denying Racism: Elite Discourse and Racism In J. Solomos \& J. Wrench (Eds.) Racism and Migration in Western Europe (pp.179-193) Oxford: Berg.

van Dijk, T. A. (1997) Political Discourse and Racism: Describing Others in Western Parliaments. In S, Riggins, The Language and Politics of Exclusion: Others in Discourse, Communication and human values (pp.31-64) London, Sage.

Verkuyten, M. (2001). "Abnormalization" of Ethnic Minorities in Conversation, British Journal of Social Psychology, 40, 257-278.

Verkuyten, M. (2005) Immigration Discourses and their Impact on Multiculturalism: A Discursive and Experimental Study, British journal of social psychology, 44, 223-241

Wetherell, M. \& Edley, N. (1999). Negotiating Hegemonic Masculinity: Imaginary Positions and Psycho-Discursive Practices, Feminism \& Psychology, 9(3), 335-356.

Wetherell, M \& Potter, J. (1992) Mapping the language of racism. Harvest Wheatsheaf: London 